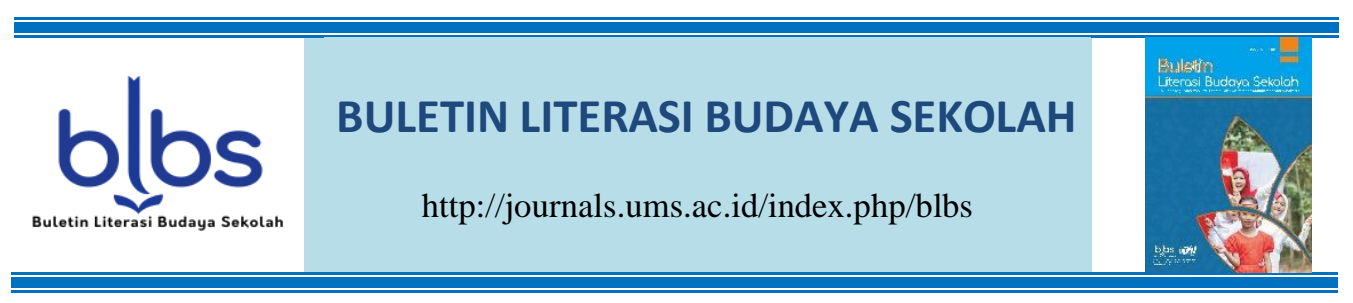

\title{
KEGIATAN BTA SEBAGAI PEMBENTUKAN KARAKTER SISWA YANG ISLAMI DI SMP MUHAMMADIYAH 4 SAMBI BOYOLALI
}

\author{
Putri Gayatri Ramadhanty ${ }^{1}$, Indah Wahyuni ${ }^{2}$ \\ 1,2 Universitas Muhammadiyah Surakarta \\ Universitas Muhammadiyah Surakarta, Surakarta, Indonesia \\ Email: putriramadhanty26@gmail.com, wahyuniindah639@gmail.com
}

\begin{tabular}{|c|c|}
\hline $\begin{array}{l}\text { Submitted: } 2020-08-19 \\
\text { Accepted: } 2020-09-09 \\
\text { Published: } 2020-12-07\end{array}$ & DOI: 10.23917/blbs.v2i2.12838 \\
\hline Keywords: & Abstract \\
\hline $\begin{array}{l}\text { Implementation } \\
\text { of Reading and } \\
\text { Writing } \\
\text { Activities } \\
\text { Motivation } \\
\text { Work } \\
\text { Programs } \\
\text { Islamic Student } \\
\text { Character }\end{array}$ & $\begin{array}{l}\text { The implementation of Al-Qur'an reading and writing activities at } \\
\text { SMP Muhammadiyah } 4 \text { Sambi Boyolali is carried out from Tuesday } \\
\text { to Thursday, which is carried out after teaching and learning } \\
\text { activities. This activity must be carried out by all students and } \\
\text { students based on their abilities. For reading and writing Al-Quran } \\
\text { Iqro 'takes place in each student's class, while for reading and } \\
\text { writing Al-Quran and Tahfidz takes place in the mosque around the } \\
\text { school. Application of Read and Write Al-Quran is the right way to } \\
\text { form an Islamic character in oneself. Among the series of activities } \\
\text { to read and write Al-Qur'an, the teacher always provides motivation, } \\
\text { guidance and responsibility to students. The person in charge of } \\
\text { reading and writing Al-Qur'an activities is the walikelas who holds } \\
\text { each grade level. The series of activities to read and write Al-Qur'an } \\
\text { are mandatory for students at SMP Muhammadiyah } 4 \text { Sambi because } \\
\text { it is a work program of the school principal himself to shape the } \\
\text { behavior and character of students who draw closer to Allah SWT. } \\
\text { Islamic student character can be formed in a student by practicing } \\
\text { good life habits and always worshiping Allah SWT. }\end{array}$ \\
\hline
\end{tabular}

\section{PENDAHULUAN}

Pendidikan adalah sesuatu yang sangat menentukan karakter seseorang, karena pendidikan memiliki tujuan untuk membimbing dan menjadikan seseorang memiliki kemampuan, pengetahuan, kecerdasan, serta keterampilan dalam menyelasaikan tugas. Pendidikan adalah hal yang paling pokok bagi manusia apalagi pendidikan agama yang saat ini berkembang secara global di Indonesia. Perguruan Tinggi di Indonesia banyak yang mengajarkan mata pelajaran keagamaan, misalnya membaca dan menulis Al-Qur'an sebagai salah satu wujud pendidikan untuk membentuk karakter manusia (Anggraeni, Barokah, dan Sukawati, 2019:33). Menurut Asmara (2013: 18) menjelaskan bahwa manusia sebagai insan dunia yang selalu berdampingan dengan makhluk hidup lain juga memiliki peran penting untuk melangsungkan kehidupan selanjutnya. Manusia 
diciptakan oleh Allah SWT yang memiliki akal, untuk menentukan arah hidupnya di masa depan oleh para generasi selanjutnya agar mencapai tujuan yang lebih baik.

Pendidikan karakter anak berkaitan erat dengan perilaku dan moral untuk kepribadian anak tersebut. Guru juga mampu menanamkan karakter kepada muridnya melalui kegiatan yang biasa dilakukan oleh sekolah itu sendiri. Pendidikan untuk anak harus dimulai sejak dini termasuk pendidikan karakter seperti anak harus berperilaku jujur, sopan dan malu untuk bersikap malas didepan orang lain yang tidak dikenalnya. Karena untuk membentuk sikap seperti itu perlu membutuhkan waktu yang tidak instan (Ridwan Abdullah Sani ; 2016:7)

Umat islam diwajibkan untuk bisa membaca Al Qur'an, karena merupakan keterkaitan antara ibadah lainnya, seperti shalat, haji, dan berdoa (Anggranti, 2016:106). Hal ini juga ditegaskan oleh Sumadi Suryabrata dalam Muhsin (2017) bahwa peran pendidik sangat besar dalam menentukan pandangan hidup siswa, karena itulah kenalilah mereka dan berikanlah mereka bimbingan. Pada dasarnya ada tiga aspek yang ingin dikembangkan dalam sebuah pendidikan, yaitu pertama aspek kognitif (cognitive learning), yang meliputi pengembangan ilmu pengetahuan, potensi, daya intelektualisme dan pengembangaan keterampilan yang diperlukan untuk menggunakan pengetahuan tersebut. Kedua aspek afektif (affective development) yang meliputi penanaman nilai-nilai moralitas dan religiusitas serta pemupukan sikap emosionalitas dan sensitivitas. Dan ketiga aspek psikomotorik (practical competence), yang meliputi peningkatan performance dalam kehidupan berbangsa, pengembangan kemampuan, adaptasi terhadap perubahan, pemupukan daya sesitivitas terhadap persoalan sosial kemasyarakatan, pembinaan kapasitas diri dan pengetahuan untuk memperluas berbagai pilihan di berbagai bidang pekerjaan, kesehatan, kehidupan keluarga dan masalah-masalah praktis lainnya (Zakiah Daradjat dalam Winata dkk, 2020:91). Penelitian Puslitbang Pendidikan Agama dan Keagamaan tentang "Efektivitas kebijakan pemerintah daerah tentang baca-tulis al-Qur'an dalam perspektif Peningkatan Mutu Pendidikan Agama" menunjukkan adanya dukungan signifikan masyarakat maupun Pemda dalam peningkatan kemampuan baca-tulis Al-Qur'an siswa di sekolah dan madrasah (Farida, 2013:351).

Kegiatan Baca Tulis Al-Qur'an merupakan salah satu sarana yang tepat untuk membangun karakter religius dan tanggung jawab kepada para siswa. Diantara rangkaian kegiatan Baca Tulis Al-Qur'an tersebut guru selalu memberikan motivasi, bimbingan dan tanggung jawab kepada peserta didik. Rangkaian kegiatan Baca Tulis Al-Qur'an wajib kepada para siswa dan siswi di SMP Muhammadiyah 4 Sambi karena merupakan program kerja dari Kepala Sekolah sendiri untuk membentuk tingkah laku dan sifat para siswa yang mendekatkan diri kepada Allah SWT. Karakter siswa yang islami dapat dibentuk dalam diri seorang siswa dengan melatih kebiasaan hidup yang baik dan selalu beribadah kepada Allah SWT.

Rangkaian Kegiatan Baca Tulis Al-Quran di SMP Muhammadiyah 4 Sambi Boyolali dilakukan pada hari selasa sampai hari kamis, yang dilakukan setelah kegiatan belajar mengajar selesai. Kegiatan ini harus dilakukan seluruh siswa dan siswi beralaskan kemampuan yang dimiliki. Untuk Baca Tulis Al-Quran Iqro' bertempat di kelas masing-masing siswa sedangkan untuk Baca Tulis Al-Quran dan Tahfidz bertempat di Masjid sekitar sekolah. Untuk kegiatan Baca Tulis Al-Qur'an yaitu setiap dipegang oleh wali kelas, namun jika wali kelas berhalangan hadir 
beliau menyerahkan tugas tersebut kepada kami selaku peserta PLP. Pembentukan karakter islami dengan memberikan motivasi dalam tujuan yaitu berkomitmen terhadap diri sendiri dengan menjalankan perintah dan menjauhi larangan-Nya, selalu bersemangat ajaran islam, memiliki keaktifan dalam suatu kegiatan yang bersifat kebaikan.

Sebuah karakter terdiri dari tiga bagian yang saling berkaitan yaitu, moral knowing (pengetahuan moral) sesuatu yang berhubungan dengan wawasan untuk membentuk sifat dan tingkah laku yang baik, moral feeling (perasaan moral) sesuatu yang berhubungan dengan perasaan seseorang dalam bertingkah laku, moral behavior (perilaku moral) sesuatu yang sering menjadi bahan pembicaraan dalam pembentukan suatu karakter. (Zubaedi, 2011:13). Keluarga memiliki peran yang sangat besar dalam mencapai keberhasilan seorang anak untuk meningkatkan pengetahuan serta kemampuan yang ada dalam dirinya. Namun, pengaruh lingkungan dari orang sekitar juga menjadi faktor dalam mempengaruhi kehidupannya.

\section{METODE}

Penulisan artikel menggunakan metode kualitatif deskriptif karena mendeskripsikan dengan cara menggambarkan dan menjelaskan rangkaian kegiatan Baca Tulis Al-qur'an yang merupakan kewajiban para siswa di SMP Muhammadiyah 4 Sambi Boyolali. Tujuan penelitian ini menggunakan metode penelitian deskriptif untuk memberikan gambaran yang memiliki fakta akan kebenaran tentang suatu kelompok, menunjukkan suatu mekanisme hubungan yang baik, menjadikan gambaran lengkap dalam bentuk lisan dan tulisan, menjadikan pemberitahuan dasar, serta dapat menjelaskan suatu subjek dari penelitian ini. Pembuatan artikel ini membutuhkan waktu selama dua minggu. Sumber data pada penelitian hasil observasi kami adalah kepala sekolah, guru beserta staf, dan siswa dengan melakukan wawancara, observasi, serta dokumentasi secara langsung secara langsung terlibat dalam kegiatan pembelajaran BTA tersebut setelah para siswa mengikuti kegiatan belajar mengajar.

\section{HASIL DAN PEMBAHASAN}

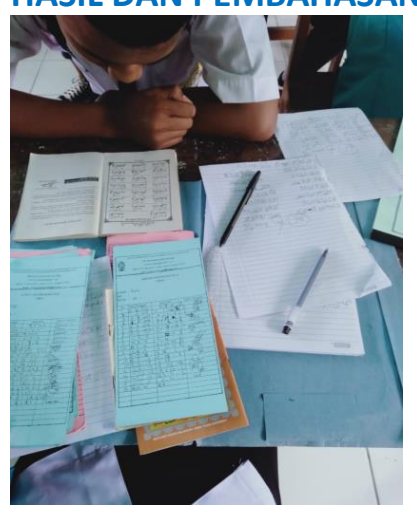

Gambar 1. Daftar Hadir BTA

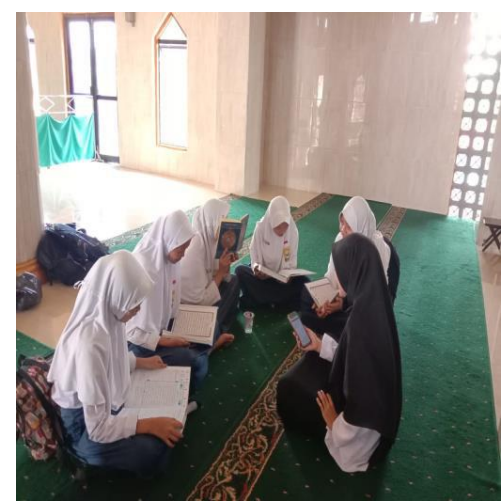

Gambar 2. Kegiatan BTA di Masjid 


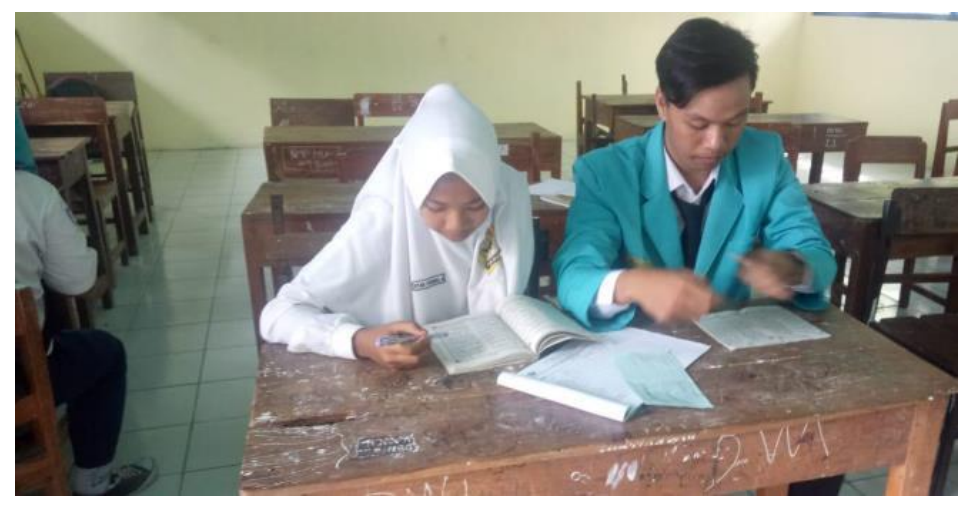

Gambar 3. Kegiatan BTA di kelas

Foto diatas merupakan foto siswa di SMP Muhammadiyah 4 Sambi saat melakukan rutinitas kegiatan Baca Tulis Al-Qur'an setelah kegiatan belajar mengajar selesai. Bisa dilihat juga pada foto diatas dimana kegiatan ini tidak dilakukan dalam satu tempat yang sama. Seperti hal nya di yang dilakukan oleh peserta PLP 1 diatas yang sedang membimbing dan mengajari beberapa siswa diantaranya kelas $7,8,9$. Sementara foto selanjutnya itu siswa kelas 9 yang sedang membaca Iq'ra dan dibimbing oleh salah satu peserta PLP 1. Rutinitas ini siswa harus mengikuti karena merupakan program dari Kepala Sekolah sendiri untuk membentuk karakter siswa yang lebih islami juga mendekatkan diri kepada Allah Swt. Selain itu untuk berperilaku sopan dan santun terhadap semua guru dan orang tua. Rangkaian kegiatan Baca Tulis Al-Qur'an ini dilaksanakan mulai hari selasa hingga kamis, sementara untuk hari jum'at itu dilakukan ekstra-kurikuler yaitu Hisbul Wathon dan untuk hari sabtu dilakukan kegiatan tambahan lainnya yaitu Tapak Suci.

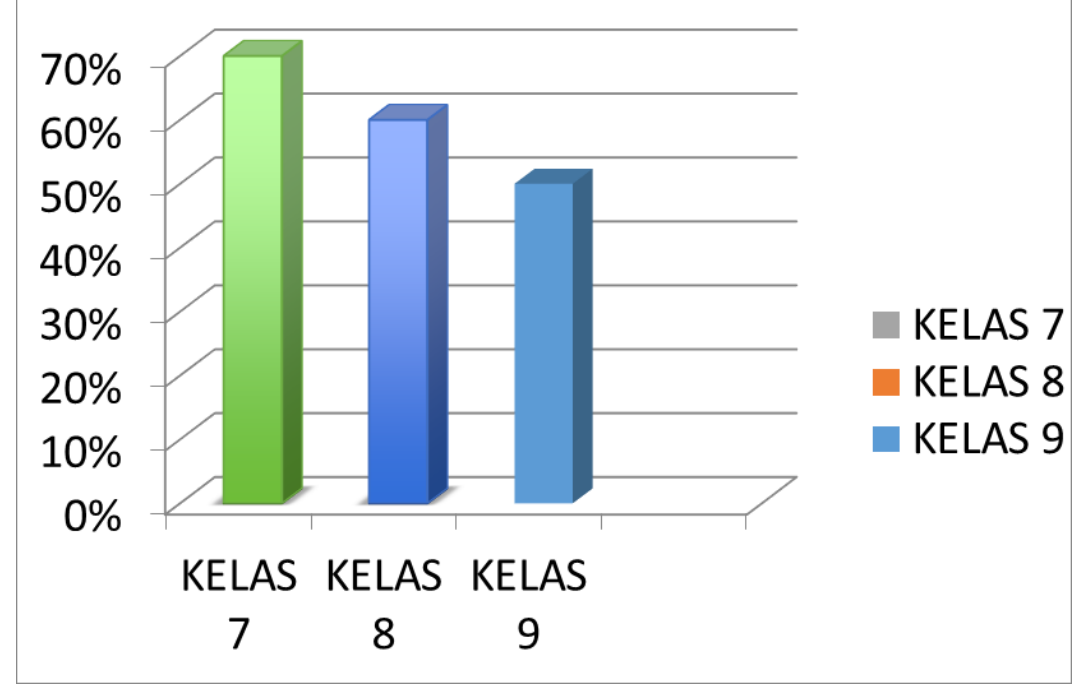

Berdasarkan hasil observasi yang kami lakukan selama kegiatan PLP 1 berlangsung kami mendapatkan data persentase untuk siswa kelas 7 yang berpartisipasi rangkaian kegiatan ini sebanyak $70 \%$, kelas 8 sebanyak $60 \%$, dan 
kelas 9 sebanyak $50 \%$ hal ini dikarenakan siswa kelas 9 ketika pembelajaran telah selesai sebagian dari mereka lebih mengutamakan untuk segera pulang kerumah dan itu berdampak kepada kelas 7 dan kelas 8 yang mencontoh perilaku dari siswa kelas 9 tersebut. Adapun dari siswa tersebut yang hanya mengisi daftar kehadiran saja tanpa mengikuti kegiatan itu sendiri.

Pendidikan karakter memiliki tujuan agar dapat mencapai suatu ukuran proses, hasil proses pengubahan sikap dan perilaku seseorang yang mengarah kepada kebaikan, berakhlak mulia secara utuh, terpadu dan serta seimbang pada standar kompetensi yang dimiliki setiap karakter seseorang. Melalui pendidikan karakter islami, siswa diharapkan mampu tanpa bantuan orang lain dalam meningkatkan pengetahuannya, mempelajari, menerapkan kebiasaan yang baik sehingga terwujud dalam kehidupan sehari-hari (Mulyasa, 2013: 9).

Karakter islami oleh seorang siswa harus dimiliki di SMP Muhammadiyah 4 Sambi. Dengan mengajarkan kebiasaan menjalankan ibadah pada Allah Swt, menjalankan yang sunnah seperti infaq yang dilakukan rutin pada hari selasa dan kamis. Dari aktivitas rutin tersebut dilakukan agar memberikan sifat positif pada setiap siswa. Penerapan karakter siswa sangatlah penting, kita tahu bahwa di jaman modern ini banyak masalah yang menjadikan hilangnya nilai-nilai agama dan merosotnya akhlak baik yang membuat keresahan dan ketidaknyamanan pada orang tua dan masyarakat yang ada disekitarnya. Salah satu contoh dari rendahnya karakter islami yaitu dalam menjalankan kewajiban sholat 5 waktu yang masih banyak siswa tinggalkan dan banyaknya siswa yang belum memiliki kemampuan baca iqro' dan al-qur'an dengan baik.

Penanggung jawab dari kegiatan Baca Tulis Al-Qur'an yaitu walikelas yang memegang masing-masing tingkatan kelas. Rangkaian kegiatan Baca Tulis Al-Qur'an wajib kepada para siswa dan siswi di SMP Muhammadiyah 4 Sambi karena merupakan program kerja dari Kepala Sekolah sendiri untuk membentuk tingkah laku dan sifat para siswa yang mendekatkan diri kepada Allah Swt. Yang dilakukan oleh SMP Muhammadiyah 4 Sambi itu sangat jarang diikuti oleh sekolah lain karena mungkin ada yang masalah waktu dan faktor lain. Kendala yang dihadapi dalam pembentukan karakter islami di SMP Muhammadiyah 4 Sambi Boyolali adalah kurangnya perhatian dari orang tua, kurangnya pengajar dalam pelaksanaan Baca Tulis Al-Qur'an, minim-nya tempat untuk pelaksanaan kegiatan BTA, serta pemberian batasan waktu untuk kegiatan BTA kurang tepat dan siswa lebih menginginkan untuk segera mengakhiri kegiatan ini. Hambatan selanjutnya adalah terbatasnya buku iqro' dan al-qur'an dari sekolah, dan ada guru dari mata pelajaran di sekolah menyuruh kepada para siswa untuk pulang setalah mata pelajaran selesai, kebanyakan siswa dari kelas IX hanya mengisi data hadir ekstra-kurikuler BTA dan tidak mengikuti kegiatan tersebut maka dari itu banyak siswa yang lebih memilih cepat pulang kerumah.

Namun demikian, hakekat pendidikan karakter memiliki makna lebih tinggi dari pendidikan moral, karena pendidikan karakter tidak hanya berkaitan dengan masalah benar-salah, tetapi bagaimana menanamkan kebiasaan tentang hal-hal yang baik dalam kehidupan, sehingga pembelajar memiliki kesadaran, dan pemahaman yang tinggi, serta kepedulian dan komitmen untuk menerapkan kebajikan dalam kehidupan sehari-hari. Dalam konteks pemikiran islam, karakter berkaitan dengan dan ikhsan (Mulyasa, 2013: 3). 
Solusi alternatif mengatasi kendala dalam pembentukan karakter siswa yang islami yaitu dengan memperbanyak pengajar dari kegiatan ini, memperbanyak buku iqro' dan Al-Qur'an, memberikan pengarahan dan motivasi agar siswa lebih rutin mengikuti kegiatan baca ini dan mengganti waktu rangkaian kegiatan ini di pagi hari setelah sholat duha berjamaah. Strategi ini mampu untuk menanggilangi penghambatan untuk pembentukan sifat dan tingkah laku yang islami siswa.

\section{SIMPULAN}

Untuk membangun karakter yang religius di SMP Muhammadiyah 4 Sambi perlu diperhatikan karena sifat dan tingkah laku mereka yang kurang sopan dan tidak santun membuat orang sekitar kurang nyaman. Dalam hal ini siswa akan lebih dapat mendekatkan diri kepada Allah Swt serta menjauhi larangan-Nya. Sebagaimana kita tahu bahwa di agama islam hukumnya wajib dalam mengetahui makna yang terkandung dalam kitab suci Al-Qur'an. Perilaku siswa yang berada di SMP Muhammadiyah 4 Sambi sendiri butuh bimbingan dari pihak yang terlibat langsung dengan para siswa seperti guru-guru disekolah tersebut. Maka dari itu kepala sekolah mengadakan kegiatan ini sebagai bentuk kegiatan indikator untuk mencerminkan karakter siswa. Masih banyak siswa yang berani melawan atau membantah perintah dari guru maupun kepala sekolah sehingga hal ini tidak patut bila tidak dibimbing dari sekarang.

Kurangnya peranan orang tua pun yang mengakibatkan karakter siswa bertingkah laku kurang sopan terhadap guru disekolah. Pembentukan karakter yang islami perlu dukungan dari orang-orang sekitar agar para siswa bisa mengambangkan kemampuan mereka ke jenjang yang lebih atas lagi, juga bisa bersikap yang baik, sopan dan santun untuk berbicara kepada orang yang lebih tua diatas mereka. Selanjutnya, agar siswa mengetahui program yang diterapkan dalam pembentukan karakter siswa yang islami, untuk meningkatkan betapa pentingnya bersikap yang ramah agar disegani sesama teman sebaya maupun orang dikenal. Selain itu adanya kegiatan ini yang dilakukan disekolah-sekolah adalah mengetahui sampai dimana kemampuan baca siswa dalam mengaji yang tidak hanya dilakukan dilingkungan rumah saja.

\section{DAFTAR PUSTAKA}

Anggraeni, Dini., Barokah, Rita Rohimatul., \& Sukawati Sary. (2019). Pengaruh Kegiatan Baca Tulis Al-Qur'an (BTQ) Terhadap Sikap Religius Mahasiswa IKIP Siliwangi. Parole, 2(1), 33-38.

Anggranti, Wiwik. (2016). Penerapan Metode Pembelajaran Baca Tulis Al Qur'an (Studi Deskriptif-Analitik di SMP Negeri 2 Tenggarong). Jurnal Intelegensia, 1(1), 106-119.

Asmara, Adi. (2013). Reboisasi Lingkungan. Bandung:CV. Cipta Pesona Sejahtera.

Farida, Erlina. (2013). Kemampuan Baca-Tulis Al-Qur'an dan Penguatan Agama Siswa Madrasah Tsanawiyah di 8 Kota Besar di Indonesia. Edukasi, 11(3), 350-367.

Muhsin, Ali. (2017). Peran Guru dalam Upaya Meningkatkan Kualitas Baca Tulis Al Qur'an di TPQ Miftahul Ulum Nglele Sumobito Jombang. Al-Murabbi, 2(2), 275-290.

Mulyasa, (2013). Manajemen Pendidikan Karakter. Bandung: Bumi Aksara. 
Ridwan Abdullah Sani. (2016). Pendidikan Karakter. Jakarta: Bumi Aksara.

Winata, Koko Adya dkk. (2020). Peningkatan Kemampuan Peserta Didik Terhadap Baca Tulis Al-Qur'an Melalui Guru Pendidikan Agama Islam. Jurnal Pendidikan Agama Islam, 6(2), 90-100.

Zubaedi. (2011). Desain Pendidikan Karakter: Konsepsi dan Aplikasinya dalam Lembaga Pendidikan. Jakarta: Kencana. 